\title{
Research Based on the Application of Geographic Information System of Prehistoric Archeology in China
}

\author{
Shidong Pei ${ }^{1^{*}}$, Qihang Wang ${ }^{2}$ \\ ${ }^{1}$ School of Social Development, Nanjing Normal University, Nanjing, Jiangsu, 210023, China \\ ${ }^{2}$ Department of History Anhui University, Hefei 230039, China \\ Email: psdlyy@gmail.com
}

\begin{abstract}
Geographic information system is an important system for geographic data analysis and processing. It involves disciplines in different fields and forms effective geographic information system software, which can be applied to the practice of prehistoric archaeology. Through the application of GIS in different stages of prehistoric archaeology, we can see the importance and scope of GIS. It is found that prehistoric archeology has an inevitable connection with geographic information systems. It has not only become an important tool for prehistoric archeology, but also has been established and comprehensively analyzed in archeological databases. It is also an effective way to comprehensively analyze the ancient people's living environment and social relationships means. Archaeologists can implement effective archeological conjectures in the process of using geographic information systems. In the process of fine archaeological analysis and site distribution, they can also effectively apply theoretical and practical analysis of geographic information systems to improve archeologists. Study of the actual work effect and archeological environment. Geographic information system not only has an important position in archeology, but should also see its deficiencies in practical applications. Gradually, according to the specific problems existing in prehistoric archeology, effective personnel training and functional analysis of archeological research have achieved different results. The archaeological environment research and reflection at this stage, through the archaeological trials and conjectures of different angles and methods, to achieve the integration of archaeological research resources, and gradually explain the scientific comprehensive analysis of archeology.
\end{abstract}

Keywords: prehistoric archeology, geographic information system, application, reflection

\section{Introduction}

The development speed and application range of GIS have gradually obtained a qualitative leap, and the practical archeological application of GIS has been realized in practical archeology. In the process of conducting archeological investigations at home and abroad, the effectiveness and scientificity of the investigations have gradually been realized. Archaeological studies of regional investigation records are more capable of solving resource problems with geographic information systems. Spatial analysis methods of GIS and important achievements in important research. Based on the digital elevation model, further graphics processing was gradually performed on the human environment and topography.

${ }^{[1]}$ Comprehensive research and application of the human-land relationship were combined with environmental studies to continuously reflect and explore the relationship between settlement distribution and the natural environment. Formed a research process of social complexity. Geographic information system can play an important and practical means in the Neolithic era to the distribution of sites and the relationship between the environment, and promote the continuous development of archaeology in China, so as to expand the comprehensive application of geographic information systems and realize higher-level geographic information system technology Integrate with archeological problems to solve practical problems of different types of archeological research in different regions.

\section{Understanding geographic information systems}

Geographic information system is a computer-based data management system for application management and space research. It can not only perform position processing on the data, but also implement effective data management. The geographic information system can not only comprehensively process data, but also carry out secondary development of system software. Gradually apply geographic information systems to different fields such as urban planning, transportation, agricultural surveying and mapping, archeological research, and cultural heritage management to achieve economic Rapid development. In the process of archaeology's continuous development, GIS is also applied to prehistoric archeology. It can not only analyze archeological research from multiple angles, but also effectively solve archeological problems and realize 
the practical application of GIS And the paradigm shift, in the development process of GIS technology, gradually realize the research and effective analysis of GIS settlements. ${ }^{[2]}$

\section{The importance of geographic information systems in archeology}

From the development trend of geographic information system, we can see that it can not only connect the science of surveying and mapping, environmental science and information technology networks, but also effectively manage and plan natural resources, and gradually carry out continuous research in the network age in economic development.

${ }^{[3]}$ Geographic information system, as an important data tool and auxiliary facility for management decision-making, has promoted the development of the geographic information industry, and also enabled China's geographic information system to be effectively researched and used. Geographic information system has not only achieved important new developments in archaeological research, but also can become an important driving force for the study of archaeological spatial characteristics.

\subsection{To lay the foundation for the development of archeology in China}

With the continuous development of western archeological theories and methods, China has made effective references in the application of geographic information systems. Archaeologists have continuously conducted multi-disciplinary research to achieve the effective development of science and technology archeology in China. In particular, the data analysis and spatial environment integration of geographic information systems allowed prehistoric archaeology to obtain a macroscopic research framework and analysis of site material information, which laid the foundation for the development of archaeology in China.

\subsection{Provide new perspectives for archaeologists}

With the continuous development of scientific and technological archaeology and environmental archaeology, geographic information systems have gradually been applied to archeological research, and the practical application of archaeological research has gradually realized the feasibility development, especially the practical application of geographic information system technology. ${ }^{[4]}$ The research carried out a reference for actual research. It also enables related archeologists to conduct monograph publishing and dissertation materials from different perspectives, so that archaeologists can conduct application analysis and database establishment from different perspectives, and gradually realize the effective application of technology, and explore geographic information systems to solve practical problems An effective approach to archeological issues.

\subsection{Significant results have been achieved in practical application of geographic information systems}

In the practical application of archaeology, GIS has gradually realized the comprehensive development of multi-angle applications from the budding stage. Not only has it achieved the continuous excavation of archeological research in China and the further development of scientific and technological archeology, but it has also allowed the GIS to carry out the ancient people's survival mode. Argument. Significant results have also been achieved in archeological studies of cultural relics, which have greatly enriched the data database content of archeological research and allowed western archeology to be applied to practical research in China.

\section{Application of geographic information system in prehistoric archeology}

The archaeological research of geographic information system is mainly a comprehensive study of environmental archaeology, especially in the management of cultural sites, it has formed an effective process of data collection, analysis and decision-making. The GIS was applied to record archaeological data of previous times in writing, and an effective historical archeology study was conducted. Prehistoric archeological research is mainly to conduct effective research on prehistoric human remains and relics, especially to gradually restore the natural environment, human physique, and social organization changes from cultural, economic, and social forms.

\subsection{Comprehensive development of archeological investigations and studies}

In the process of conducting regional archeological investigations, China has gradually realized archaeological investigations in areas such as the Daling River Basin, Southeast Shandong, and Yuncheng Basin, which have cooperated overseas. It can also use GIS to conduct prehistoric and Han settlement settlements in Southeast Shandong coastal areas. research. The spatial analysis method of the information system was used to gradually obtain the settlement distribution. Through the analysis of geographic information system software, the relationship between the distribution of the ruins in 
the environment and the cultural background was explored, and it played an important role in the restoration of the ancient environment and ancient human life.

\subsection{The comprehensive research on man-land relationship}

Archeology realizes the restoration of the ancient human environment in more aspects from different perspectives, and realizes the effective connection between the natural environment and the settlement distribution. It is necessary to actively apply geographic information systems to archeological science and technology research, so that cultural changes can be used to achieve environmental changes. The research on personal scientific background shows the importance of geographic information systems. These include distances between rivers, landforms and soil types, and slopes for research and analysis.

\subsection{Other applications}

Geographic information system can not only conduct macro analysis of materials, but also divide settlement evolution into different settlement areas. The effectiveness of the method and the comprehensiveness of environmental background analysis gradually apply GIS technology to other fields. For example, to study the population, realize the application of spatial analysis methods, determine the scope of the resource area of the site, and then gradually study the resource area and the social development process from the perspective of population and land use conditions and resources. Using the different analysis methods of the geographic analysis system, the effective results of archeological research were obtained, and the relationship between the ancient people's living behavior and the specific livelihood and the environment were analyzed.

\section{Reflection on geographic information system in prehistoric archeology}

The practical application of GIS in archeology has been developed in the preliminary stage of prehistoric archeology. Although GIS has played an important role in promoting archaeological science and technology, there are still some problems in the practical application of GIS It not only requires the actual knowledge and structural strength of archaeologists, but also increases archaeological research methods. At the same time, it is necessary to improve and perfect archaeological research methods, strengthen the research of archaeological theoretical knowledge, and be able to apply the theory of middle and high stages to archeological analysis in. While learning from western scientific theories, it is also necessary to carry out effective agricultural origin research on geographic information systems through cultural ecology.

\subsection{Strengthening micro-research and archeological fineness of sites}

Although geographic information systems can promote the research of archaeological macro-framework, in the archeological micro-research still need to strengthen the theories of refinement, social interaction and organization of the ancients, to find effective material basis. Micro-study can realize the unification of information about prehistoric archeology and paleoenvironment. During the research of GIS background materials, the analysis of the relationship between the nature of the site and the environment, and the application of new theories of archaeology were gradually realized. Especially in multidisciplinary research, it is more able to explain the analysis of the origin of agriculture and the relationship between people.

\subsection{Strengthening the knowledge of archeologists}

The development of archaeological research requires not only the participation of geographic information systems, but also the effective application of computer mapping systems and the establishment of archaeological database information systems in actual operation. Archaeologists need to perform scenarios during archeological processes. ${ }^{[6]}$ Analysis and information analysis. All these links are inseparable from the participation of archeologists. In the application of geographic information technology to the development of actual archeology, the practical problems of archeology need to be solved, and archeologists need to expand the knowledge structure. Not only must you have knowledge of environment and ecology, but also master the relevant content of the humanities and social sciences, and gradually use effective theoretical research and archeological methods to form an effective expansion of your own knowledge and the long-term goal construction of archeological theory. , To form a clear mind to solve problems in practice.

\section{Conclusion}

In the study of prehistoric archeology in China, the effective application of geographic information systems has gradually been realized. Prehistoric archeology includes research content in paleoanthropology, paleontology, geology and ethnology, and gradually restores the natural environment and Related changes in the relationship between ancient 
people and society, in the continuous change of modern scientific and technological archeological culture, to realize the comprehensive application of prehistoric archeology technology, the effective processing of data in the geographic information system and the continuous demonstration of archeological data. Archaeologists continue to improve their knowledge structure and archeological system, will play the greatest role of geographic information systems in archeology, and can visualize geographic information systems from information records, material integration, drawing graphics and archaeological arguments. Technical processing, in practical applications, constantly establishes interaction with archeological issues through the Internet field, so as to achieve new developments in archeology.

\section{References}

[1] Zhang Yinglan. The Application Status and Prospects of GIS in Archeology. Journal of Northwest University (Philosophy and Social Sciences Edition). 2006; 36(6).

[2] Qi Wuyun, Zhou Chenghu, Wang Rongxun. Application Types of Geographic Information System in Archeological Research. Huaxia Archaeology. 2005; 2: p. 108.

[3] Wang Xingtao, Zhai Shikui. Development of Geographic Information Technology System and Its Application in Marine Field. Marine Geology and Quaternary Geology. 2003; 05.

[4] Mei Qibin, Xiong Xia. Application of Geographic Information System in Archeology. Journal of Zhejiang Wanli University. 2005; 04. 